\title{
Mice doubly deficient in the midkine and pleiotrophin genes exhibit deficits in the expression of $\beta$-tectorin gene and in auditory response
}

\author{
Peng Zou ${ }^{1}$, Hisako Muramatsu ${ }^{1,2}$, Michihiko Sone ${ }^{3}$, Hideo Hayashi ${ }^{3}$, Tsutomu Nakashima ${ }^{3}$ \\ and Takashi Muramatsu ${ }^{1,4}$ \\ ${ }^{1}$ Department of Biochemistry, Nagoya University Graduate School of Medicine, Showa-ku, Nagoya, Japan; \\ ${ }^{2}$ Division of Animal Models, Center for Neurological Disease and Cancer, Nagoya University Graduate School \\ of Medicine, Showa-ku, Nagoya, Japan; ${ }^{3}$ Department of Otolaryngology, Nagoya University Graduate School \\ of Medicine, Showa-ku, Nagoya, Japan and ${ }^{4}$ Department of Health Science, Faculty of Psychological and
} Physical Sciences, Aichi Gakuin University, Nisshin, Aichi, Japan

\begin{abstract}
$\alpha$-Tectorin and $\beta$-tectorin are major noncollagenous proteins of the tectorial membrane, which plays a crucial role in the reception of sonic signals in the cochlea. Midkine and pleiotrophin are closely related proteins that serve as growth factors and cytokines. In mice doubly deficient in the midkine gene and pleiotrophin gene, expression of $\beta$-tectorin mRNA was nearly abolished in the cochlea on day 1 and 7 after birth. Expression of $\alpha$ tectorin mRNA was unaffected in the double knockout mice, and expression of $\beta$-tectorin mRNA was not altered in mice deficient in only the midkine or pleiotrophin gene. In newborn wild-type mice, both midkine and pleiotrophin were expressed in the greater epithelial ridge of the cochlea, in which $\beta$-tectorin mRNA was strongly expressed. These results indicate that either midkine or pleiotrophin is required for significant expression of $\beta$-tectorin. In agreement with the view that $\beta$-tectorin is essential for normal auditory function, mice doubly deficient in both midkine and pleiotrophin genes exhibited very severe auditory deficits. We observed that mice deficient in either midkine or pleiotrophin gene were also impaired in their auditory response, but the level of the deficit was generally low or moderate. The present finding illustrates the importance of growth factor expression in the cochlea for auditory function.

Laboratory Investigation (2006) 86, 645-653. doi:10.1038/labinvest.3700428; published online 17 April 2006
\end{abstract}

Keywords: auditory response; cochlea; growth factor; midkine; pleiotrophin; $\beta$-tectorin

Genetic studies have revealed molecular basis of deficits in auditory function in certain cases. ${ }^{1-8}$ However, the entire picture of abnormalities causing auditory deficits is not yet provided. So far, $\alpha$ tectorin is one of the most studied molecules in relation to auditory function. Mutation of the $\alpha$ tectorin gene leads to auditory deficits in humans, ${ }^{1,2}$ and mice deficient in the $\alpha$-tectorin gene also exhibit deficits in auditory function. ${ }^{3} \alpha$-Tectorin is a major protein of the tectorial membrane in the cochlea, in which the sound-induced movement of the basilar membrane is transmitted to the sensory hair bundles

Correspondence: Dr H Muramatsu, PhD, Department of Biochemistry, Nagoya University Graduate School of Medicine, 65 Tsurumai-cho, Showa-ku, Nagoya 466-8550, Japan.

E-mail: hmurama@med.nagoya-u.ac.jp

Received 15 October 2005; revised and accepted 13 March 2006; published online 17 April 2006 by the tectorial membrane. $\beta$-Tectorin is also abundantly expressed in the tectorial membrane. ${ }^{9}$ $\alpha$ - and $\beta$-Tectorins have protein motifs involved in sperm-egg adhesions; the motifs appear to function in the formation of filament-based matrices or gels. ${ }^{9,10}$ Although direct evidence of the participation of $\beta$-tectorin in auditory function is lacking, its expression is decreased upon thyroid hormone deficiency, ${ }^{11}$ which causes auditory impairment. Furthermore, $\beta$-tectorin is an antigen that causes autoimmune hearing loss. ${ }^{12}$ Here, we report that mice doubly deficient in midkine (MK) and pleiotrophin (PTN) are impaired in $\beta$-tectorin expression and exhibit severe deficits in auditory function.

MK and PTN, also called heparin-binding growthassociated molecule (HB-GAM), are low molecular weight basic proteins with closely related structures and serve as growth/differentiation factors and cytokines. $^{13-19}$ The expression of these factors is 
temporally and spatially regulated; intense expression is usually observed in tissues during the embryonic and perinatal periods. ${ }^{20,21}$ Overexpression of these factors, especially MK, in adult tissues is associated with malignancy and inflammatory diseases. ${ }^{16,18,22-25}$

Both MK and PTN are strongly expressed in the central nervous system during development ${ }^{20,21}$ and promote the neurite outgrowth, and migration and survival of neurons. ${ }^{16,18,19,26-28}$ Furthermore, PTN promotes differentiation of neural progenitor cells. $^{29,30}$ Mice that are deficient in the MK or PTN gene exhibit certain behavioral abnormalities. ${ }^{31,32}$ Overexpression studies also indicate that MK promotes neurogenesis in Xenopus and zebra fish embryos. ${ }^{33,34}$ In a recent study in zebra fish, which have two species of MK due to gene duplication, it was established that a form of MK plays essential roles in the formation of the medial floor plate, one of the most ventral neural tube structures. ${ }^{35}$ The factors are also expressed in specific regions during development of the sensory organs, suggesting roles in the developmental process. ${ }^{20,21} \mathrm{MK}$ and PTN have $45 \%$ sequence identity at the protein level, and share many of the in vitro activities. ${ }^{14,16,18,19,36,37}$ Therefore, we inferred that the functions of MK and those of PTN frequently overlap. Thus, to clarify the roles of these factors in vivo, we generated mice doubly deficient in both the MK and PTN genes. As a result of many in vitro activities of these factors to neuronal cells, we focused to the possible abnormalities in the nervous and sensory systems of the doubly deficient mice. Consequently, we were able to demonstrate that expression of growth factors in the cochlea is important in normal auditory function.

\section{Materials and methods}

\section{Knockout Mice}

Mice deficient in the $\mathrm{MK}$ gene $(M d k)^{24}$ were generated as described previously. Mice deficient in the PTN gene (Ptn) were also described ${ }^{38}$ (Muramatsu et al, submitted for publication). After the backcrossing of $\mathrm{Mdk}^{+/-}$or $\mathrm{Ptn}^{+/-}$to C57BL/6J mice for 10 generations, $\mathrm{Mdk}^{+/-}$and $\mathrm{Ptn}^{+/-}$mice were mated with each other to generate wild-type (WT), MK knockout (MKKO) PTN knockout (PTNKO) and double knockout (DKO) mice, which were used in the present study. The female sterility of DKO will be described elsewhere (Muramatsu $\mathrm{H}$ et al, submitted for publication).

\section{DNA Microarray Analysis}

At day 14 after birth, total RNA from the whole brain was isolated with an RNeasy column (QIAGEN Sciences, Tokyo, Japan) according to the manufacturer's protocol. The gene expression profile was analyzed with a DNA microarray using a CodeLink
Expression Bioarray System (Amersham Biosciences) provided by Kurabo (Osaka, Japan).

\section{Preparation of Specimens from Cochleas}

Six cochleas from postnatal day (P) 7 or P14 mice were fixed in $4 \%$ paraformaldehyde in phosphatebuffered saline (PBS; $\mathrm{pH} 7.4$ ) for 1 day at $4^{\circ} \mathrm{C}$, washed three times with PBS, and decalcified in $0.5 \mathrm{M}$ EDTA ( $\mathrm{pH} 7.5)$ for 7 days at $4^{\circ} \mathrm{C}$. After dehydration through a graded series of ethanol solutions, the specimens were embedded in paraffin. Sections were cut at $5 \mu \mathrm{m}$, placed on glass slides coated with 3-aminopropyltriethoxysilane, and then subjected to staining with hematoxylin and eosin (HE), or to in situ hybridization. Total cochlear RNA was isolated from six cochleas of WT, MKKO, PTNKO or DKO mice using Isogen (Wako, Tokyo, Japan) according to the manufacturer's directions.

\section{Reverse Transcription (RT)-PCR}

Total cochlear RNA (500 ng) was subjected to RT in a $20 \mu \mathrm{l}$ reaction mixture containing $40 \mathrm{Us}$ of RNase inhibitor (Invitrogen, Carlsbad, CA, USA) and $0.5 \mu \mathrm{g}$ of oligo dT primers (Invitrogen). In all, $50 \mathrm{U}$ of SuperScript ${ }^{\mathrm{TM}}$ II reverse transcriptase (Invitrogen) was used to synthesize double-stranded cDNA. The 50- $\mu \mathrm{l}$ PCR mixture contained $2 \mu \mathrm{l}$ of the product of the RT, $5 \mu$ l of $10 \times$ PCR buffer, $2 \mathrm{mM}$ dNTP, $2.5 \mathrm{U}$ of ExTaq DNA polymerase (Takara, Kyoto, Japan), and $20 \mathrm{pmol}$ each of the primers. After preincubation at $94^{\circ} \mathrm{C}$ for $5 \mathrm{~min}$, PCR was performed for 30 cycles of $30 \mathrm{~s}$ at $94^{\circ} \mathrm{C}, 40 \mathrm{~s}$ at $60^{\circ} \mathrm{C}$, and $90 \mathrm{~s}$ at $72^{\circ} \mathrm{C}$, followed by one extension-cycle for $5 \mathrm{~min}$ at $72^{\circ} \mathrm{C}$. The oligonucleotides used for amplification were as follows: MK (5'-ATGCAGCACCGAGGCTTCTT-3' and $5^{\prime}$-CTTTGACTTGGTCTTGGAGG- $\left.3^{\prime}\right)$; PTN $\left(5^{\prime}\right.$ ACTGGCGCCGAGTGCAAACAG- $3^{\prime}$ and $5^{\prime}$-GAGCTT GCCACAGGGCTTGGA-3'); $\alpha$-tectorin (5'-AGCAAC GACAAGCTTCGGTACTTC- $3^{\prime}$ and $5^{\prime}$-TCTTGCAGG GATCCGGTCACACAG- $3^{\prime}$ ); $\beta$-tectorin (5'-GAAATCA TGCACTCCGAATAAAGC- $3^{\prime}$ and $5^{\prime}$-CGAGGGGGTG GCCCAGCAGCTATT-3'); $\beta$-actin ( $5^{\prime}$-GTGGGCCGCT CTAGGCACCA- $3^{\prime}$ and $5^{\prime}$-CGGTTGGCCTTAGGGTT CAGGGGG-3').

\section{Real-Time Quantitative PCR}

Real-time quantitative PCR for $\alpha$-tectorin, $\beta$-tectorin and $\beta$-actin was carried out using the TaqMan probe and TaqMan Universal PCR Master Mix according to the manufacture's directions. Expression of each gene was normalized to the amount of $\beta$-actin RNA. We calculated relative amounts of each product using the comparative CT method as described in the user bulletin of ABI Prism 7500 Sequence Detection System (Applied Biosystems, Foster City, CA, USA). 


\section{In Situ Hybridization}

MK cDNA (nucleotides 1-420) ${ }^{39}$ or PTN cDNA (nucleotides 270-773) ${ }^{40}$ was inserted into Bluescript $\mathrm{KSII}+$ (Stratagene). The PCR product of $\alpha$-tectorin (469 bp) or $\beta$-tectorin (576 bp) was also subcloned into Bluescript. These plasmids were digested to completion with either HindIII or BamH1. Digoxigenin-labeled antisense RNA probes were transcribed from HindIII cut clones using T7 RNA polymerase and sense RNA probes were transcribed from BamH1 cut clones using T3 RNA polymerase (DIG RNA labeling kit, Boehringer Mannheim, Mannheim, Germany). In situ hybridization was performed as described previously. ${ }^{41}$

\section{Determination of Thyroid Hormones}

Thyroid hormone levels in sera were determined using four mice of each genotype at 8 weeks after birth employing Gamma Coat $\mathrm{T}_{3}$ II and Gamma Coat $\mathrm{M}$ Total $\mathrm{T}_{4}$ (DiaSorin Inc, Stillwater, MN, USA).

\section{Determination of Auditory Responses}

Auditory brain stem responses (ABRs) were measured in four 8-week-old mice from the WT, MKKO,
PTNKO and DKO groups. After the mice were anesthetized using a mixture of ketamine hydrochloride, xylazine, and acepromazine maleate administered subcutaneously, needle electrodes were inserted into the vertex (positive), occiput (negative), and hindpaw (ground). Tone bursts of $4 \mathrm{~ms}$ duration with a rise and fall time of $1 \mathrm{~ms}$ at frequencies of $8,12,16$, and $20 \mathrm{kHz}$ were produced using a sound stimulator (DPS-725, Dia Medical System Co., Tokyo, Japan), and a speaker (10TH800, Technics, Osaka, Japan). A total of 512 tone-burstevoked responses were obtained with amplifier filters set below 100 and above $3 \mathrm{kHz}$. The amplified responses were averaged by a computer (PowerLab 4/20, ADInstruments, Castle Hill, Australia) and displayed on a monitor. ABRs were obtained by decreasing the stimuli in $5-\mathrm{dB}$ steps from a maximum intensity of $100 \mathrm{~dB}$ SPL

\section{Results}

\section{DNA Microarray Analysis of the Brain of MK/PTN DKO Mice}

In order to detect abnormalities in the brain of 14day-old DKO mice, which were deficient in both the MK and PTN genes, a DNA microarray analysis was

Table 1 Downregulated genes in the brains of MK/PTN DKO, MKKO or PTNKO mice

\begin{tabular}{|c|c|c|c|}
\hline Comparison & Gene description & Changes (Folds) & GenBank accession No. \\
\hline DKO to WT & $\begin{array}{l}\text { Hox-3.1homeo gene } \\
\text { FKSG27 } \\
\text { Olfactory receptor Mor41-1 } \\
\beta \text {-Tectorin } \\
\text { Killer cell lectin-like receptor } \\
\text { Olfactory receptor Mor202-20 } \\
\text { Formyl peptide receptor, related sequence } 3 \\
\text { Vomeronasal } 1 \text { receptor, C29 } \\
\text { Olfactory receptor Mor182-5 } \\
\text { Scinderin }\end{array}$ & $\begin{array}{l}-84.8 \\
-36.8 \\
-25.9 \\
-24.6 \\
-21.7 \\
-19.9 \\
-16.4 \\
-15.6 \\
-12.8 \\
-10.5\end{array}$ & $\begin{array}{l}\text { NM_010466 } \\
\text { NM_153134 } \\
\text { NM_146754 } \\
\text { NM_009348 } \\
\text { NM_010649 } \\
\text { NM_146575 } \\
\text { NM_008040 } \\
\text { NM_134184 } \\
\text { NM_146486 } \\
\text { NM_009132 }\end{array}$ \\
\hline MKKO to WT & $\begin{array}{l}\text { Hox-3.1homeo gene } \\
\text { FKSG27 } \\
\text { Serine (or cysteine) proteinase inhibitor } \\
\text { Olfactory receptor Mor202-20 } \\
\text { Olfactory receptor Mor41-1 } \\
\text { Junctophilin } 1 \\
\text { Killer cell lectin-like receptor } \\
\text { Formyl peptide receptor, related sequence } 3 \\
\text { Olfactory receptor Mor182-5 } \\
\text { Cartilage oligomeric matrix protein }\end{array}$ & $\begin{array}{l}-86.8 \\
-53.1 \\
-31.7 \\
-24.8 \\
-19.8 \\
-18.5 \\
-17.0 \\
-17.0 \\
-15.9 \\
-15.4\end{array}$ & $\begin{array}{l}\text { NM_010466 } \\
\text { NM_153134 } \\
\text { NM_027548 } \\
\text { NM_146575 } \\
\text { NM_146754 } \\
\text { NM_020604 } \\
\text { NM_010649 } \\
\text { NM_008040 } \\
\text { NM_146486 } \\
\text { NM_016685 }\end{array}$ \\
\hline PTNKO to WT & $\begin{array}{l}\text { Homeo box A9 } \\
\text { Forkhead box P2 } \\
\text { Gonadotropin releasing hormone receptor } \\
\text { Mucolipin } 3 \\
\text { Islet cell autoantigen } 1 \\
\text { Eph receptor B4 } \\
\text { Casitas B-lineage lymphoma-like } 1 \\
\text { Sjogren syndrome antigen B } \\
\text { Peptidyl arginine deiminase type } 1 \\
\text { Nik related kinase }\end{array}$ & $\begin{array}{r}-90.7 \\
-42.7 \\
-14.6 \\
-12.8 \\
-8.8 \\
-6.9 \\
-6.8 \\
-6.5 \\
-6.0 \\
-5.1\end{array}$ & $\begin{array}{l}\text { NM_010456 } \\
\text { NM_053242 } \\
\text { NM_010323 } \\
\text { NM_134160 } \\
\text { NM_010492 } \\
\text { NM_010144 } \\
\text { NM_134048 } \\
\text { NM_009278 } \\
\text { NM_011059 } \\
\text { NM_013724 }\end{array}$ \\
\hline
\end{tabular}

In all, 10 genes, which were most severely suppressed for expression, were shown. 
performed. We found that the expression of several genes was severely suppressed in DKO mice as compared to WT mice (Table 1). However, the expression of the majority of such genes was also suppressed in MKKO mice, which lacked only the MK gene (Table 1). On the other hand, in PTNKO mice the number of severely suppressed genes decreased, and the reduced expression was not reproduced in DKO mice. Most probably, expression of PTN in the absence of MK results in disturbed expression of some genes. The gene, the expression of which decreased most dramatically in DKO mice, encoded $\beta$-tectorin, which is known to be strongly expressed in the cochlea. ${ }^{9}$ Thus, we focused our attention on the cochlea.

Expression of MK, PTN, $\alpha$-Tectorin and $\beta$-Tectorin in the Cochlea of WT and DKO Mice

RT-PCR analysis revealed that MK and PTN were strongly expressed in the cochlea of WT mice 1 week after birth, and then the expression decreased and was undetectable by week 8 after birth (Figure 1). The strong expression of MK in the cochlea of newborn mice is consistent with a previous report. ${ }^{42} \alpha$ - and $\beta$-tectorins are known to be strongly expressed during the neonatal period, but they were hardly detectable in the adult..$^{43}$ In the cochlea of 1 -week old DKO mice, $\beta$-tectorin expression was undetectable by RT-PCR analysis but that of $\alpha$-tectorin was unaffected. In mice singly deficient in either MK or PTN, the cochlea tectorin levels were not significantly affected (Figure 1).

Quantitative RT-PCR analysis revealed that the level of $\beta$-tectorin mRNA in the cochlea of DKO mice was $8 \%$ of that in the WT mice at 1 week after birth (Figure 2). Even by this analysis, $\alpha$-tectorin levels did not differ between WT and DKO mice. Also, we found a small amount of $\alpha$ - and $\beta$-tectorin RNA in the brains of 7-day old and 14-day old WT mice, confirming the finding of the DNA microarray analysis.

We performed in situ hybridization to correlate the expression of MK, PTN and tectorins in the cochlea of 1-week old mice (Figure 3). Both MK and PTN were expressed in the striavasularis and the greater epithelia ridge and surrounding structures (Figure 3a, b); these signals were not detected using sense probes. The strongest signal for both $\alpha$-tectorin and $\beta$-tectorin was observed in the greater epithelial ridge (Figure 4). The expression of $\beta$-tectorin in this area was abolished in DKO mice, but that of $\alpha$-tectorin persisted (Figure 4). The overlapping expression of $\beta$-tectorin, $\mathrm{MK}$ and PTN in the greater epithelia ridge, and their absence in DKO mice strongly suggested that $\beta$-tectorin expression was directly regulated by MK and PTN. As thyroid hormone levels are known to affect the expression of $\beta$-tectorin, ${ }^{11}$ we determined the levels of thyroid hormones in sera of 8-week old mice and found that they did not differ between WT and DKO mice: $\mathrm{T}_{3}$

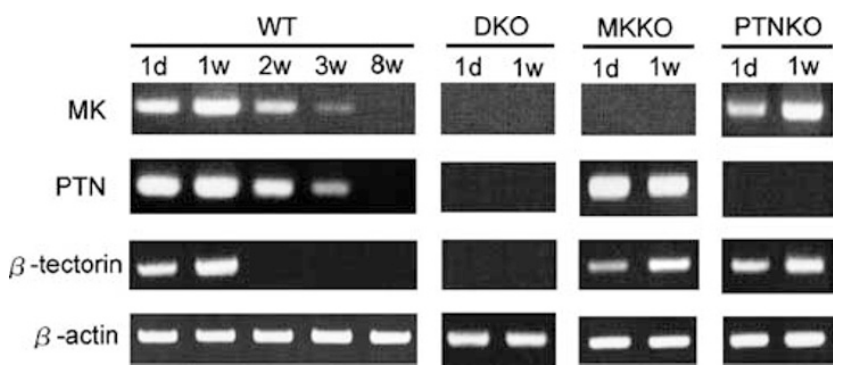

Figure 1 RT-PCR analysis for the gene expression in the cochlea of WT, MKKO, PTNKO or DKO mice from 1day (1d) to 8 weeks (8w) after birth. Total cochlear RNA was isolated from six cochlea of WT, MKKO, PTNKO or DKO mice and PCR products were electrophoresed using $2 \%$ agarose gel.

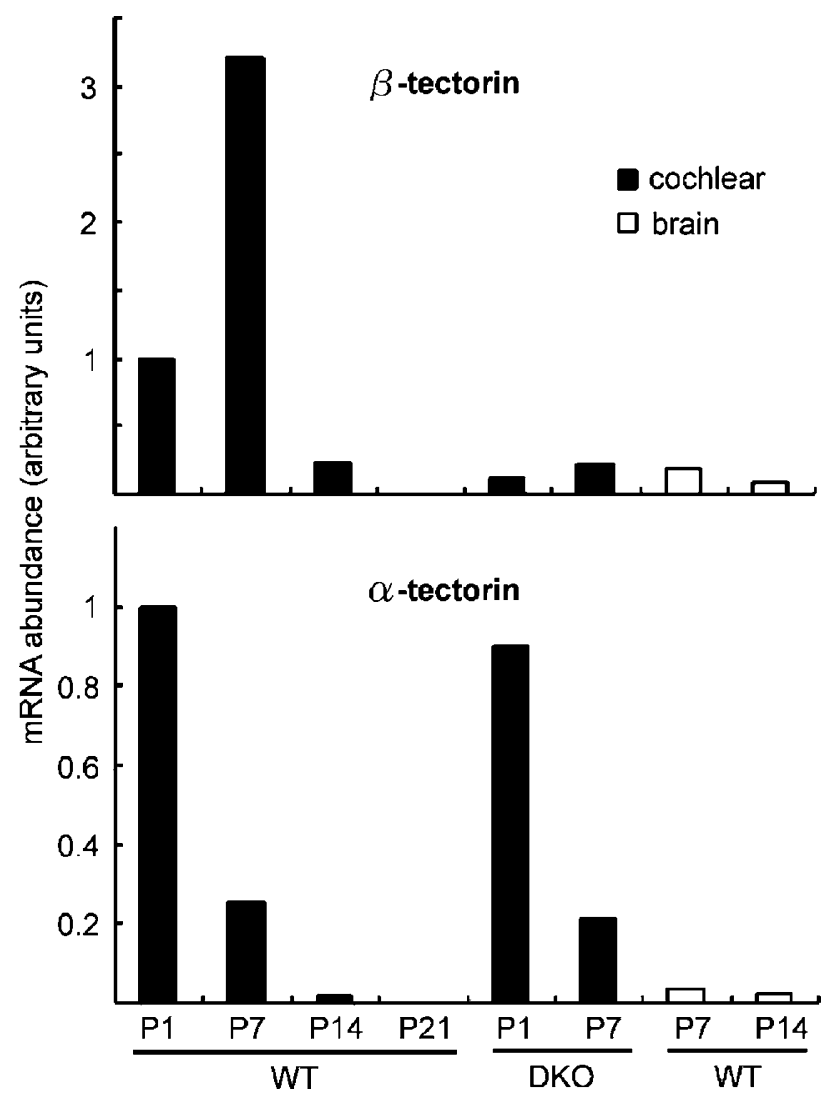

Figure 2 Quantification of mRNA of $\alpha$ - and $\beta$-tectorin in the cochlea (closed bars) or brain (open bars) of WT and DKO mice. Abundance is the ratio to $\beta$-actin mRNA in the same sample.

and $\mathrm{T}_{4}$ levels were, respectively, $0.65 \pm 0.11$ and $2.74 \pm 0.44 \mathrm{ng} / \mathrm{ml}$ in WT and $0.54 \pm 0.17$ and $2.49 \pm 0.62 \mathrm{ng} / \mathrm{ml}$ in DKO mice. Furthermore, the levels of mRNAs for thyroid stimulating hormone (TSH) $\beta$-subunit, glycoprotein hormone $\alpha$-subunit, which serves as TSH $\alpha$-subunit, TSH releasing hormone and TSH releasing hormone receptor in the brain of 2-week-old mice did not differ between WT and DKO mice as examined by DNA microarray analysis. All mRNAs were expressed in good levels to ensure the accuracy of the analysis. The result indicates that abnormality in the level of TSH did not occur in DKO mice. 
MK probe

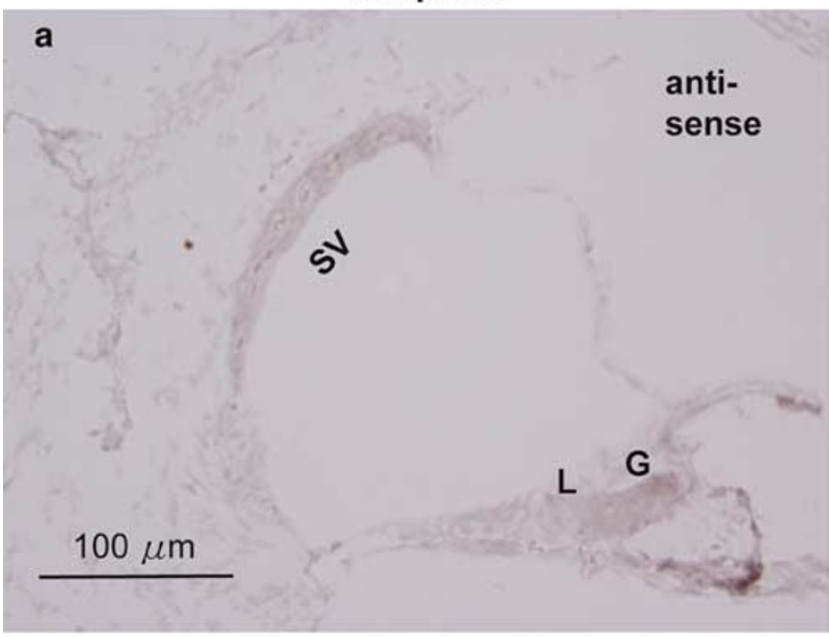

C

sense
PTN probe d

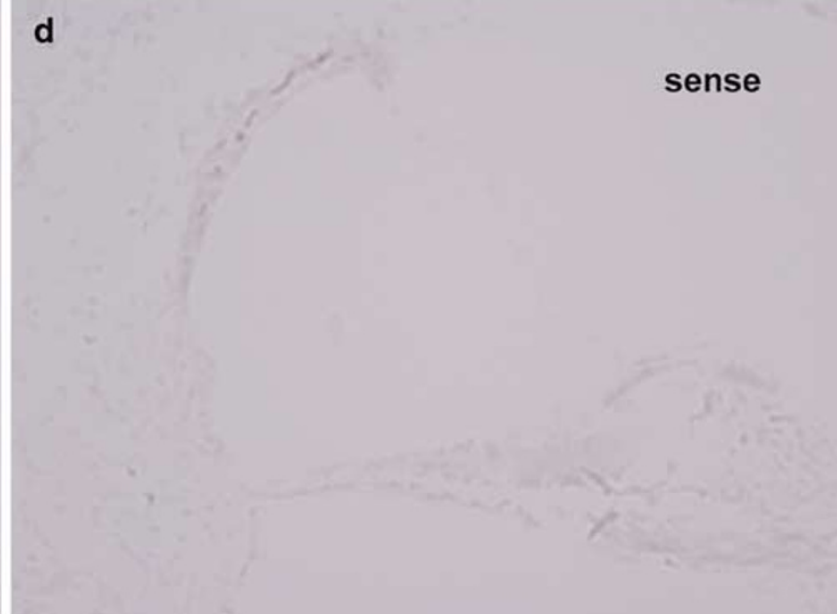

Figure 3 In situ hybridization to reveal MK and PTN expression in the cochlea of WT C57BL/6J mice one week after birth. Sections were hybridized with antisense (a, b) or sense (c, d) probes for MK (a, c) and PTN (b, d). Positions of the stria vascularis (SV), and cells of the greater (G) and lesser (L) epithelial ridges are indicated in a and b. Bar, $100 \mu \mathrm{m}$.

\section{Deficit of Auditory Response in the Knockout Mice}

Using 8-week old male mice, we compared the auditory responses of WT, single knockout and DKO mice by measuring ABRs (Table 2). MKKO and PTNKO mice exhibited low to moderate levels of auditory deficits. Although WT animals responded at about $25 \mathrm{~dB}$, MKKO and PTNKO mice generally responded at around $50 \mathrm{~dB}$. On the other hand, DKO mice were found to show a very severe phenotype. None of four DKO mice exhibited a response (shown as $105 \mathrm{~dB}$ ) to low frequency sound $(8-12 \mathrm{kHz})$. Some DKO mice responded to the strongest $(100 \mathrm{~dB})$ high-frequency sound $(16-20 \mathrm{kHz})$, and others did not. Thus, DKO mice with little $\beta$-tectorin were severely impaired in their auditory function. Significant morphological difference was not detected between the cochlea of WT mice and that of DKO mice (Figure 5).

\section{Discussion}

Tectorial membranes in the cochlea play a role in transmitting the mechanical signal of a sound to hairy cells. $\alpha$-Tectorin and $\beta$-tectorin are major noncollagenous proteins of tectorial membranes and their mRNAs are expressed strongly in the cochlea of newborn mice, but scarcely in adult mice, probably reflecting the slow turnover of these proteins. ${ }^{43}$ Expression of $\beta$-tectorin was nearly abolished in the cochlea of newborn mice doubly deficient in the MK and PTN genes. An obvious question is whether the loss of expression is a direct consequence of the absence of the factors in the cochlea or is an indirect effect of systemic changes. We believe that the disappearance of $\beta$-tectorin is the direct consequence of the loss of the growth factors, since both MK and PTN were expressed where $\beta$-tectorin expression was prominent. Even though $\beta$-tectorin mRNA level decreases upon 

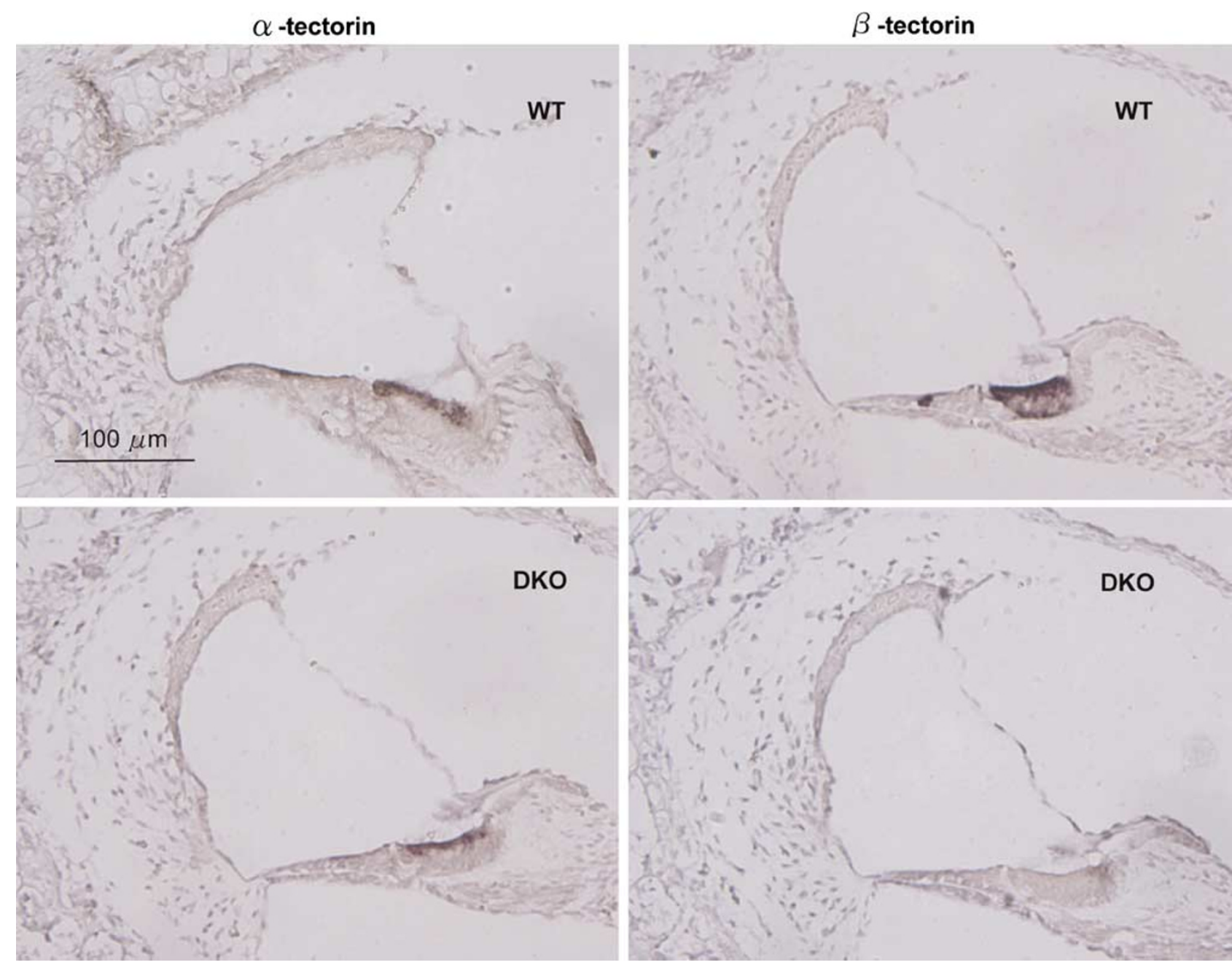

Figure 4 In situ hybridization to detect expression of $\alpha$ - and $\beta$-tectorin in the cochlea of WT or DKO mice 1 week after birth. Staining with the antisense probe is shown. Sense probes gave staining as seen in $\beta$-tectorin DKO. Bar, $100 \mu \mathrm{m}$.

Table 2 Deficits in auditory response in MKKO, PTNKO and DKO mice

\begin{tabular}{lcccr}
\hline $\begin{array}{l}\text { Frequencies } \\
(\mathrm{kHz})\end{array}$ & \multicolumn{4}{c}{ Thresholds $(\mathrm{dB} S P L)$} \\
\cline { 2 - 5 } & $W T$ & MKKO & PTNKO & WKO \\
\hline 8 & & & & \\
12 & $32.5 \pm 2.9$ & $50.0 \pm 4.1^{*}$ & $52.5 \pm 2.9^{*}$ & $105 \pm 0^{*, * *}$ \\
16 & $22.5 \pm 2.9$ & $40.0 \pm 4.1^{*}$ & $38.8 \pm 4.8$ & $105 \pm 0^{*, * *}$ \\
20 & $18.8 \pm 2.9$ & $45.0 \pm 8.2^{*}$ & $48.8 \pm 4.8^{*}$ & $102.5 \pm 2.9^{*, * *}$ \\
& $27.5 \pm 2.9$ & $55.0 \pm 4.1^{*}$ & $71.3 \pm 7.5^{*}$ & $103.8 \pm 2.5^{*, * *}$ \\
\hline
\end{tabular}

ABRs were determined using 4 eight-week-old male mice for each genotype (WT, PTNKO, MKKO or DKO). The threshold was defined as the lowest intensity producing a clearly visible first peak of wave. The ABR threshold was defined as $105 \mathrm{~dB}$ SPL, if the mouse did not respond to an intensity of $100 \mathrm{~dB}$ SPL. The average thresholds \pm s.d. are shown. All four of DKO mice exhibited the value of $105 \mathrm{~dB}$ at eight and $12 \mathrm{kHz}$. At $16 \mathrm{kHz}$, two DKO mice exhibited the value of $105 \mathrm{~dB}$, and the remaining two mice did that of $100 \mathrm{~dB}$. At $20 \mathrm{kHz}$, three DKO mice exhibited the value of 105 and one mouse did that of 100 ${ }^{*} P<0.01$ compared to WT mice; ${ }^{*} P<0.01$ compared to MKKO or PTNKO mice.

thyroid hormone deficiency in the rat, the level of suppression is not as severe as found in the present study. ${ }^{11}$ We also confirmed that the thyroid hormone level was not different between WT and DKO mice 8 weeks after birth, and that the mRNA levels of TSH, TSH-releasing hormone and the receptor in the brain of 2-week-old mice were not significantly different between WT and DKO mice as shown by DNA microarray analysis.

The reason of the low to moderate levels of auditory deficits in MKKO or PTNKO mice is not clear at the present stage of analysis. In contrast, severe auditory deficit in DKO mice was accompanied by the suppression of $\beta$-tectorin. While evidence accumulates for an essential function of $\alpha$-tectorin in hearing, only indirect evidence is provided for the role of $\beta$-tectorin. Upon thyroid hormone deficiency, the $\beta$-tectorin level decreases with a concomitant reduction in hearing; ${ }^{11}$ but one can argue that a possible abnormality in some other part of the ear causes the deficit. Loss of $\beta$-tectorin expression is the much likely reason of the severe auditory deficit in DKO mice, while additive effects of MK deficiency and PTN deficiency cannot be completely eliminated. Thus, the results of the present investigation provide further supporting 

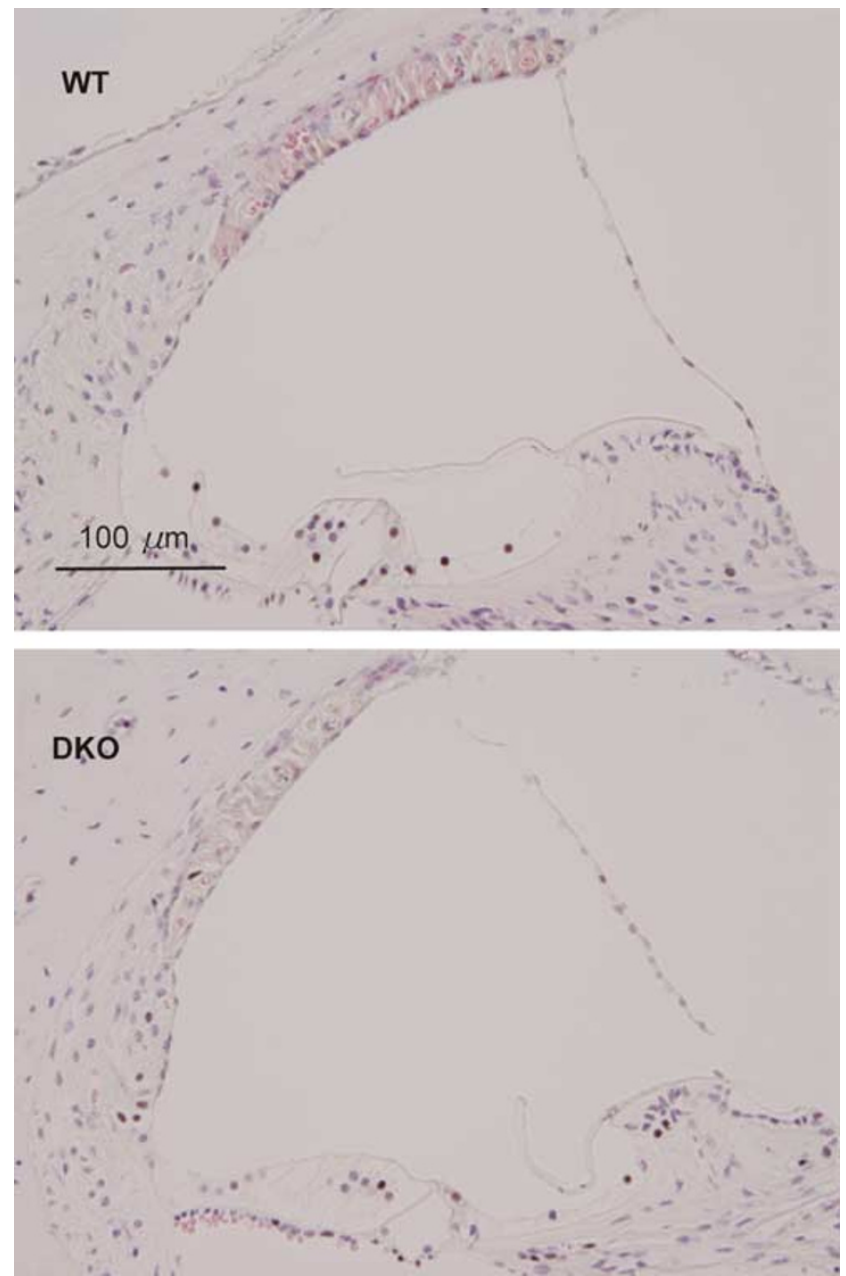

Figure 5 HE-staining of sections of the cochlea from WT or DKO mice 8 weeks after birth. Bar, $100 \mu \mathrm{m}$.

evidence, but not a definitive evidence for the role of $\beta$-tectorin in auditory function.

Although MK and PTN have been shown to share many functions in vitro, such as neurite outgrowth, migration of neurons, migration of osteoblasts and clustering of acetylcholine receptors, ${ }^{18,36,37}$ there are few reports demonstrating that the two factors share activities in vivo. Very recently, both MK and PTN have been shown to regulate the renin-angiotensin system. ${ }^{44,45}$ The present report also verifies the shared activities.

The present study revealed a novel route leading to auditory deficits, namely deficiency of growth factors and the signaling systems at the cochlea during critical time of development. Although only low to moderate levels of auditory deficit are observed in MK or PTN single deficiency, auditory deficit in DKO mice is at a very severe level. While dual loss of MK and PTN in patients is rather unlikely, abnormality in a signaling receptor for these factors can cause congenital disorder of auditory response. The receptors for MK consists of multiple molecules, namely integrins, lowdensity lipoprotein receptor-related protein (LRP), proteoglycans such as receptor-type tyrosine phosphatase and probably Alk kinase. ${ }^{46-49}$ It is highly likely that the receptor for PTN shares most components with the MK receptor. ${ }^{18,26,50-52}$ As a candidate causing the receptor malfunction, it may be worthwhile to examine abnormalities of certain sulfotransferases, since oversulfation of glycosaminoglycan chains is required for the receptor activity. ${ }^{53}$

\section{Acknowledgements}

We thank Ms K Kobori for technical assistance. This work was supported by grants from the Ministry of Education, Culture, Sports, Science and Technology of Japan (14082202, 15390103, 15COEF01-09).

\section{Duality of interest}

None declared.

\section{References}

1 Verhoeven K, Van Laer L, Kirschhofer $\mathrm{K}$, et al. Mutations in the human $\alpha$-tectorin gene cause autosomal dominant non-syndromic hearing impairment. Nat Genet 1998;19:60-62.

2 Mustapha M, Weil D, Chardenoux S, et al. An $\alpha$-tectorin gene defect causes a newly identified autosomal recessive form of sensorineural pre-lingual non-syndromic deafness, DFNB21. Hum Mol Gen 1999;8:409-412.

3 Legan PK, Lukashkina VA, Goodyear RJ, et al. A targeted deletion in $\alpha$-tectorin reveals that the tectorial membrane is required for the gain and timing of cochlear feedback. Neuron 2000;28:273-285.

4 Thompson PM, Vidal C, Giedd JN, et al. Mapping adolescent brain change reveals dynamic wave of accelerated gray matter loss in very early-onset schizophrenia. Proc Natl Acad Sci USA 2001;98: 11650-11655.

5 Li J, Verkman AS. Impaired hearing in mice lacking aquaporin-4 water channels. J Biol Chem 2001;276: 31233-31237.

6 Chinnery PF, Elliott C, Green GR, et al. The spectrum of hearing loss due to mitochondrial DNA defects. Brain 2000;123:82-92.

7 Stojkovic T, Latour P, Vandenberghe A, et al. Sensorineural deafness in X-linked Charcot-Marie-Tooth disease with connexin 32 mutation (R142Q). Neurology 1999;52:1010-1014.

8 Matsushita T, Hayashi H, Kunishima S, et al. Targeted disruption of mouse ortholog of the human MYH9 responsible for macrothrombocytopenia with different organ involvement: hematological, nephrological, and otological studies of heterozygous KO mice. Biochem Biophys Res Commun 2004;325:1163-1171.

9 Killick R, Legan P K, Malenczak C, et al. Molecular cloning of chick $\beta$-tectorin, an extracellular matrix molecule of the inner ear. J Cell Biol 1995;129: $535-547$. 
10 Legan PK, Rau A, Keen JN, et al. The mouse tectorins. Modular matrix proteins of the inner ear homologous to components of the sperm-egg adhesion system. J Biol Chem 1997;272:8791-8801.

11 Knipper M, Richardson G, Mack A, et al. Thyroid hormone-deficient period prior to the onset of hearing is associated with reduced levels of $\beta$-tectorin protein in the tectorial membrane: implication for hearing loss. J Biol Chem 2001;276:39046-39052.

12 Solares CA, Edling AE, Johnson JM, et al. Murine autoimmune hearing loss mediated by CD4+ T cells specific for inner ear peptides. J Clin Invest 2004;113: 1210-1217.

13 Deuel TF, Zhang N, Yeh HJ, et al. Pleiotrophin: a cytokine with diverse functions and a novel signaling pathway. Arch Biochem Biophys 2002;397:162-171.

14 Iwasaki W, Nagata K, Hatanaka H, et al. Solution structure of midkine, a new heparin-binding growth factor. EMBO J 1997;16:6936-6946.

15 Kadomatsu K, Tomomura M, Muramatsu T. cDNA cloning and sequencing of a new gene intensely expressed in early differentiation stages of embryonal carcinoma cells and in mid-gestation period of mouse embryogenesis. Biochem Biophys Res Commun 1988; 151:1312-1318.

16 Rauvala H. An 18-kd heparin-binding protein of developing brain that is distinct from fibroblast growth factors. EMBO J 1989;8:2933-2941.

17 Li YS, Milner PG, Chauhan AK, et al. Cloning and expression of a developmentally regulated protein that induces mitogenic and neurite outgrowth activity. Science 1990;250:1690-1694.

18 Muramatsu T. Midkine and pleiotrophin: two related proteins involved in development, survival, inflammation and tumorigenesis. J Biochem 2002;132: 359-371.

19 Rauvala H, Peng HB. HB-GAM (heparin-binding growth-associated molecule) and heparin-type glycans in the development and plasticity of neuron-target contacts. Prog Neurobiol 1997;52:127-144.

20 Kadomatsu K, Huang RP, Suganuma T, et al. A retinoic acid responsive gene MK found in the teratocarcinoma system is expressed in spatially and temporally controlled manner during mouse embryogenesis. J Cell Biol 1990;110:607-616.

21 Mitsiadis TA, Salmivirta M, Muramatsu T, et al. Expression of the heparin-binding cytokines, midkine (MK) and HB-GAM (pleiotrophin) is associated with epithelial-mesenchymal interactions during fetal development and organogenesis. Development 1995; 121:37-51.

22 Horiba M, Kadomatsu K, Nakamura E, et al. Neointima formation in a restenosis model is suppressed in midkine-deficient mice. J Clin Invest 2000;105:489-495.

23 Maruyama K, Muramatsu H, Ishiguro N, et al. Midkine, a heparin-binding growth factor, is fundamentally involved in the pathogenesis of rheumatoid arthritis. Arthritis Rheum 2004;50:1420-1429.

24 Sato W, Kadomatsu K, Yuzawa Y, et al. Midkine is involved in neutrophil infiltration into the tubulointerstitium in ischemic renal injury. J Immunol 2001; 167:3463-3469.

25 Takei Y, Kadomatsu K, Matsuo S, et al. Antisense oligodeoxynucleotide targeted to midkine, a heparinbinding growth factor, suppresses tumorigenicity of mouse rectal carcinoma cells. Cancer Res 2001;61: 8486-8491.
26 Maeda N, Noda M. Involvement of receptor-like protein tyrosine phosphatase $\zeta /$ RPTPbeta and its ligand pleiotrophin/heparin-binding growth-associated molecule (HB-GAM) in neuronal migration. J Cell Biol 1998;142:203-216.

27 Michikawa M, Kikuchi S, Muramatsu H, et al. Retinoic acid responsive gene product, midkine (MK), has neurotrophic functions for mouse spinal cord and dorsal root ganglion neurons in culture. J Neurosci Res 1993;35:530-539.

28 Muramatsu $\mathrm{H}$, Shirahama $\mathrm{H}$, Yonezawa $\mathrm{S}$, et al. Midkine (MK), a retinoic acid-inducible growth/ differentiation factor: immunochemical evidence for the function and distribution. Dev Biol 1993;159: 392-402.

29 Hienola A, Pekkanen M, Raulo E, et al. HB-GAM inhibits proliferation and enhances differentiation of neural stem cells. Mol Cell Neurosci 2004;26:75-88.

30 Jung CG, Hida $\mathrm{H}$, Nakahira $\mathrm{K}$, et al. Pleiotrophin mRNA is highly expressed in neural stem (progenitor) cells of mouse ventral mesencephalon and the product promotes production of dopaminergic neurons from embryonic stem cell-derived nestin-positive cells. FASEB J 2004;18:1237-1239.

31 Nakamura E, Kadomatsu K, Yuasa S, et al. Disruption of the midkine gene (Mdk) resulted in altered expression of a calcium binding protein in the hippocampus of infant mice and their abnormal behaviour. Genes Cells 1998;3:811-822.

32 Pavlov I, Voikar V, Kaksonen M, et al. Role of heparinbinding growth-associated molecule (HB-GAM) in hippocampal LTP and spatial learning revealed by studies on overexpressing and knockout mice. Mol Cell Neurosc 2002;20:330-342.

33 Yokota C, Takahashi S, Eisaki A, et al. Midkine counteracts the activin signal in mesoderm induction and promotes neural formation. J Biochem 1998;123: 339-346.

34 Winkler C, Moon RT. Zebrafish mdk2, a novel secreted midkine, participates in posterior neurogenesis. Dev Biol 2001;229:102-118.

35 Schafer M, Rembold M, Wittbrodt J, et al. Medial floor plate formation in zebrafish consists of two phases and requires trunk-derived Midkine-a. Genes Dev 2005; 19:897-902.

36 Peng HB, Ali AA, Dai Z, et al. The role of heparinbinding growth-associated molecule (HB-GAM) in the postsynaptic induction in cultured muscle cells. J Neurosci 1995;15:3027-3038.

37 Zhou H, Muramatsu T, Halfter W, et al. A role of midkine in the development of the neuromuscular junction. Mol Cell Neurosci 1997;10:56-70.

38 Ochiai K, Muramatsu H, Yamamoto S, et al. The role of midkine and pleiotrophin in liver regeneration. Liver Int 2004;24:484-491.

39 Tomomura M, Kadomatsu K, Matsubara S, et al. A retinoic-acid responsive gene, $\mathrm{MK}$, found in the teratocarcinoma system. Heterogeneity of the transcript and the nature of the translation product. J Biol Chem 1990;265:10765-10770.

40 Merenmies J, Rauvala H. Molecular cloning ot the 18-kDa growth-associated protein of developing brain. J Biol Chem 1990;265:16721-16724.

41 Fan QW, Kadomatsu K, Uchimura K, et al. Embigin/ basigin subgroup of the immunoglobulin superfamily: Different modes of expression during mouse embryogenesis and correlated expression with carbohydrate 
antigenic markers. Dev Growth Differ 1998;40: 277-286.

42 Jia XQ, Nakashima T, Kadomatsu K, et al. Expression of midkine in the cochlea. Hear Res 2001;160:10-14.

43 Rau A, Legan PK, Richardson GP. Tectorin mRNA expression is spatially and temporally restricted during mouse inner ear development. J Comp Neurol 1999;405:271-280.

44 Herradon G, Ezquerra L, Nguyen T, et al. Pleiotrophin is an important regulator of the renin-angiotensin system in mouse aorta. Biochem Biophys Res Commun 2004;324:1041-1047.

45 Ezquerra L, Herradon G, Nguyen T, et al. Midkine, a newly discovered regulator of the renin-angiotensin pathway in mouse aorta: significance of the pleiotrophin/midkine developmental gene family in angiotensin II signaling. Biochem Biophys Res Commun 2005;333:636-643.

46 Muramatsu H, Zou P, Suzuki H, et al. $\alpha 4 \beta 1-$ and $\alpha 6 \beta 1$ integrins are functional receptors for midkine, a heparinbinding growth factor. J Cell Sci 2004;117:5405-5415.

47 Maeda N, Ichihara-Tanaka K, Kimura T, et al. A receptor-like protein-tyrosine phosphatase $\mathrm{PTP} \zeta /$ $\operatorname{RPTP} \beta$ binds a heparin-binding growth factor midkine. Involvement of arginine 78 of midkine in the high affinity binding to PTP $\zeta$. J Biol Chem 1999;274: 12474-12479.

48 Muramatsu H, Zou K, Sakaguchi N, et al. LDL-receptor related protein as a component of the midkine receptor. Biochem Biophys Res Commun 2000;270: 936-941.

49 Stoica GE, Kuo A, Powers C, et al. Midkine binds to anaplastic lymphoma kinase (ALK) and acts as a growth factor for different cell types. J Biol Chem 2002; 277:35990-35998.

50 Raulo E, Chernousov MA, Carey DJ, et al. Isolation of a neuronal cell surface receptor of heparin binding growth-associated molecule (HB-GAM). Identification as N-syndecan (syndecan-3). J Biol Chem 1994;269: 12999-13004.

51 Stoica GE, Kuo A, Aigner A, et al. Identification of anaplastic lymphoma kinase as a receptor for the growth factor pleiotrophin. J Biol Chem 2001;276: 16772-16779.

52 Shibata Y, Muramatsu T, Hirai M, et al. Nuclear targeting by the growth factor midkine. Mol Cell Biol 2002;22:6788-6796.

53 Muramatsu T, Muramatsu H, Kaneda N, et al. Recognition of glycosaminoglycans by midkine. Methods Enzymol 2003;363:365-376. 